\title{
PASADO Y REVOLUCIÓN EN KARL MARX Y WALTER BENJAMIN
}

\author{
Erika Lipcen $^{1}$ \\ Universidad Nacional de Córdoba (UNC) \\ (D) https://orcid.org/0000-0002-3561-0306
}

\section{RESUMEN:}

El presente trabajo busca reconstruir una tensión entre el pensamiento de Marx y Benjamin en relación al valor que cada uno le otorga a la memoria. En principio, podría afirmarse que estos autores asumen puntos de vista contrapuestos: mientras en El Dieciocho Brumario Marx sostiene que toda apelación al pasado es superstición, por lo que la revolución no puede sacar de allí su lírica; para Benjamin, el cambio revolucionario cita al pasado. Lo que llama la atención, sin embargo, es que Benjamin en la Tesis XIV afirma que el salto al pasado que él reivindica es "la revolución tal y como la entendió Marx". Nuestro objetivo aquí será indagar los motivos por los que Benjamin incluye esta referencia a Marx, considerando que él conocía su negativa a que la revolución se nutriera del pasado.

PALABRAS CLAVE: memoria; revolución; superstición; Marx; Benjamin.

\section{PAST AND REVOLUTION IN KARL MARX AND WALTER BENJAMIN}

\begin{abstract}
:
This paper studies a tension between Marx's and Benjamin's thought, in connection with the different ways they regard memory. In principle, it could be argued that these authors assume opposing points of view: while in The Eighteen Brumaire Marx argues that any recourse to the past is superstition; for Benjamin, the revolutionary change refers to the past. However, what calls our attention is that Benjamin in his Thesis XIV maintains that the leap to the past that he defends is "the revolution as Marx has understood it". Our aim here is to explain why Benjamin included this
\end{abstract}

\footnotetext{
1 Cursa el Doctorado en Filosofía en la Facultad de Filosofía y Humanidades de la Universidad Nacional de Córdoba, Argentina. Es becaria del CONICET. E-mail: erikalipcen@hotmail.com
} 
reference to Marx if he knew about his refusal to accept any reference to the past.

KEYWORDS: memory; revolution; superstition; Marx; Benjamin.

En El Dieciocho Brumario de Luis Bonaparte, aquel estudio histórico dedicado al análisis del período que va desde la revolución de 1848 al golpe de estado de Luis Bonaparte en 1852, encontramos algunos de los famosos pasajes en los cuales Karl Marx diferencia la revolución proletaria de la burguesa, a partir de la relación que cada una de ellas guarda con la memoria. Recordemos que en este texto, publicado originalmente en la revista Die Revolution dirigida desde los Estados Unidos por su amigo Joseph Weydemeyer, Marx afirma que la revolución proletaria que debe llevarse a cabo en el siglo XIX, sólo puede iniciarse si primero logra dejar atrás "toda adoración supersticiosa del pasado" (MARX, 1998, p. 16). Para el autor, el problema de las revoluciones burguesas era que precisaban vincular sus luchas con las antiguas, para así ocultar el verdadero contenido de aquello por lo que peleaban: "[necesitan] remontarse a los recuerdos de la historia universal para pasmarse con su propio contenido" (Ibídem.). Es este el caso de Robespierre y sus colegas, quienes, según Marx, hallaban en la antigua Roma "las ilusiones" que los llevaban a no reparar en el contenido propiamente burgués de sus luchas (Ibídem. pp. 13-14). Mientras que la inscripción objetiva de sus batallas tenía un contenido burgués limitado -se correspondía con la instauración de la sociedad burguesa moderna, sus ilusiones, en cambio, los posicionaban en el centro de una gran tragedia histórica. Esta operación ilusoria era precisamente la que hacía que su interés burgués particular pasara por universal, y su propio desarrollo de clase por el de la historia como tal:

(...) cuando [los burgueses] se disponen a sublevarse y sublevar el estado de las cosas, a crear algo inusitado en estos tiempos de crisis y rebelión es precisamente cuando, con miedo, conjuran en su auxilio los espíritus de ataño, se disfrazan con sus nombres, sus consignas de guerra, sus vestimentas, para interpretar una nueva escena de la historia universal con ese traje de vejez respetable y esas palabras prestadas (Ibídem., p. 14).

En contraste con las revoluciones burguesas, la revolución proletaria que Marx propugna, implica poner en cuestión y liberarse de "la herencia de todas las generaciones muertas" (Ibídem., p. 13); supone independizarse de la influencia supersticiosa que ejerce la memoria. Las rememoraciones del pasado, al impedir que seamos conscientes de lo que pasa en la efectiva 
realidad social, y no permitir que asumamos nuestras verdaderas condiciones de existencia, tampoco posibilitan que engendremos verdaderos cambios sociales. Según Marx, el modo de no engañarse y de asumir la propia condición de clase, es dejar atrás el pasado: "permitir que los muertos entierren a sus muertos" (ibídem., p. 16). Es por eso que exhorta a que la revolución proletaria no saque su poesía del pasado, sino del futuro ${ }^{2}$.

Varios autores han mantenido que estas afirmaciones desarrolladas en El Dieciocho Brumario, son exactamente inversas a las que el filósofo judío alemán Walter Benjamin expone en sus Tesis Sobre el concepto de historia, redactadas en 1940 durante su exilio. En principio, este contraste radicaría en que mientras el imperativo revolucionario de Marx es el olvido, para Benjamin se trata, por el contrario, de lanzarse al pasado para rescatar la memoria de los vencidos.

Según Benjamin, la praxis revolucionaria se inspira en ciertos recintos del pasado que han quedado cerrados. En este sentido, en sus materiales preparatorios para las Tesis, por ejemplo, escribía:

Para el pensador revolucionario la oportunidad revolucionaria propia de cada momento tiene su banco de pruebas en la situación política existente. Pero la verificación no es menor si se efectúa valorando la capacidad de apertura de que dispone cada instante para abrir determinadas estancias del pasado hasta ahora clausuradas. La entrada en esa estancia coincide de lleno con la acción política (...) (BENJAMIN, 2009, p. 307).

Ese pasado clausurado, cuya apertura es política, es un "pasado trunco" (OYARZÚN ROBLES, 1996, p. 29) que no pudo realizarse en su presente, pero que aún contiene un reclamo por las injusticias acontecidas y el latido de sus esperanzas y utopías frustradas. La acción política parte de escuchar las voces que vienen de esas estancias cerradas del pasado; voces

\footnotetext{
${ }^{2}$ Resulta interesante recordar en este punto la lectura de Renato Janine Ribeiro quien sostiene que con esta crítica a las evocaciones del pasado que, en última instancia, apunta a desenmascarar la ideología que garantiza la preservación de un determinado orden, Marx prolonga la crítica de los modernos contra la imaginación. Para Hobbes, por ejemplo, la imaginación, al ser pasible de ser manipulada por el poder eclesiástico, nos impedía acceder a la paz e incluso a la felicidad. Marx continuaría esa crítica a la imaginación esclavizante al decir que lo que aplasta a los hombres es el peso de las imágenes que tienen del pasado. La revolución proletaria -la única que según Marx puede detener el mecanismo de repetición y engendrar verdaderos acontecimientos, por estar los intereses del proletariado en contradicción con la naturaleza del sistema social- consistiría, a diferencia de la revolución burguesa, en un trabajo de la razón que desmontaría los fundamentos del pensamiento y del poder vigentes. Es decir, la revolución proletaria coincidiría con el proceso de la crítica, exigiendo que se tome conciencia de las figuras de lo imaginario para que éste deje de ser opresivo y se puedan efectuar verdaderos cambios $(C f$. JANINE RIBEIRO, 1998, pp. 107-165).
} 
que han quedado acalladas y desechadas por la historia que ha llegado hasta hoy: "¿Acaso no nos roza un hálito del aire que envolvió los precedentes? ¿Acaso no hay en las voces a las que prestamos oídos un eco de otras, enmudecidas ahora?" (BENJAMIN, 1996, p. 48). Para Benjamin, ese pasado frustrado está inconcluso y aguarda ser actualizado: espera ser "redimido" de su fracaso.

De esta manera, el filósofo berlinés explícitamente se distanciaba de tesis como las de Max Horkheimer, para quien "[1]a injusticia pasada ha sucedido y está conclusa" (BENJAMIN, 2005, p. 473). En el Libro de los Pasajes, alude a una carta que Horkheimer le escribiera en marzo de 1937 y en la cual éste sostenía que la injusticia, el horror y el dolor del pasado son irreparables ${ }^{3}$. Es decir, para este autor el pasado no permanece inconcluso ni abierto, afirmar lo contrario -sostener el carácter no cerrado del sufrimiento pasado y de las esperanzas latentes- es "teología" (Ibídem., p. 473). Para Benjamin, en cambio, el pasado no es algo ya concluido, no permanece inamovible y fijo: "la historia no es sólo una ciencia, sino no menos una forma de rememoración. Lo que la ciencia ha 'establecido', puede modificarlo la rememoración" (Ibídem.). Entre las generaciones pasadas y las actuales existe un "secreto acuerdo", una "débil fuerza mesiánica" que las vincula y "sobre la cual el pasado reclama derecho" (BENJAMIN, 1996). Esta "débil fuerza" exige a las generaciones presentes escuchar aquellas voces que reclaman por sus derechos pendientes, prestar oídos a las exigencias del pasado y, de esta manera, actualizarlo, redimirlo de su frustración. Como explica Reyes Mate, "la recordación tiene por objeto rescatar del pasado el derecho a la justicia (...), leer los proyectos frustrados de los que está sembrada la historia no como costos del progreso sino como injusticias pendientes" (MATE, 2009, p. 259). Hay momentos del pasado que esperan la oportunidad de ser citados por el presente, de entrar con él en una "constelación" y ser así sacados de la oscuridad sus deseos de futuro que han sido mutilados. Es a partir de estas citas que Benjamin encuentra la posibilidad de que se dé la novedad; es precisamente de ellas que saca su lírica el cambio presente. Por eso, este recurso al pasado es esencialmente político. La política encuentra su poesía en las posibilidades pasadas aún latentes de redención. Es precisamente desde ese lazo con el pasado que resulta posible, para el autor, pensar un nuevo presente.

Ahora bien, lo que llama la atención es que -pese a esta evidente diferencia entre Marx y Benjamin respecto al valor que cada uno le otorga al pasado- encontramos que Benjamin en su Tesis XIV afirma que el "salto" revolucionario al pasado que él propone consiste en la revolución tal y como la entendió Marx: el "salto bajo el libre cielo de la historia es el (salto)

\footnotetext{
${ }^{3}$ En esta misma línea, en "El Estado autoritario" Horkheimer mantenía que "[e]n la historia (...) es irrevocable lo malo: las posibilidades frustradas, la felicidad que se dejó escapar, el asesinato con o sin procedimiento jurídico, aquello que el gobierno hace a las personas" (HORKHEIMER, 1972, p. 105).
} 
dialéctico, como el cual concibió Marx la revolución" (BENJAMIN, 1996, p. 61$)^{4}$. Sabemos que Benjamin había leído El Dieciocho Brumario de Luis Bonaparte en el año 1938, en la casa de su amigo Bertolt Brecht, en Svendborg [Cf. WIZISLA, 2000, p. 683). Entonces, ¿por qué motivo incluyó esta referencia a Marx en la Tesis XIV, si conocía acerca de su negativa a que la revolución se nutriera del pasado? En lo que sigue, buscaremos plasmar algunas reflexiones producto del intento de dar una respuesta a este interrogante.

II

En "Historia y paradigmas en Marx y Benjamin" (SAZBÓN, 2002, p. $164)^{5}$, el autor argentino José Sazbón compara a los dos pensadores, prestando atención a una serie de temas que forman parte de la tradición marxista. Puntualmente, en lo que respecta a la problemática que planteamos acerca de la referencia a Marx en la Tesis XIV, en un breve pasaje de su ensayo, Sazbón señala que el concepto de revolución marxiano funciona en dicha Tesis como un "contraejemplo", tanto de las citas del pasado que lleva a cabo la moda, como de los revolucionarios franceses (Cf. Ibídem., p. 164).

La Revolución francesa -afirmaba Benjamin- se comprendía a sí misma como una Roma rediviva. Citaba a la antigua Roma tal como la moda cita un viejo atuendo. La moda tiene el barrunto de lo actual, donde quiera que éste se mueva la espesura de lo antaño (BENJAMIN, 1996, p. 61).

Para Sazbón, el hecho de que Benjamin equipare aquí las formas de apelar al pasado de la moda y las de la Revolución Francesa, muestra que "ambas participan de [una] misma propensión mixtificatoria (SAZBÓN, 2002, p. 165). No sólo las citas de la moda, en su recurrente fusión de lo nuevo y lo siempre-igual, clausuran toda dialéctica emancipadora, también "la

\footnotetext{
4 Tesis XIV: "La historia es objeto de una construcción cuyo lugar no es el tiempo homogéneo y vacío, sino aquel pletórico de tiempo-ahora. Así para Robespierre, la antigua Roma era un pasado cargado de tiempo-ahora, que él hacía saltar en el continuum de la historia. La Revolución Francesa se comprendía a sí misma como una Roma Rediviva. Citaba a la antigua Roma tal como la moda cita a un viejo atuendo. La moda tiene el barrunto de lo actual, donde quiera que éste se mueva la espesura de antaño. Ella es el salto de tigre hacia lo pretérito. Sólo que tiene lugar en una arena en la cual manda la clase dominante. El mismo salto bajo el libre cielo de la historia es el (salto) dialéctico, como el cual concibió Marx la revolución" (BENJAMIN, 1996, p. 61).

${ }^{5}$ Este texto fue la intervención del autor en el Simposio internacional dedicado a Walter Benjamin que se realizó en Buenos Aires en 1992. Entre los trabajos de Sazbón relacionados con este tema, cabe destacar también "La historia en las 'Tesis' de Benjamin: problemas de interpretación" (SAZBÓN, 2002) y "El legado teórico de la Escuela de Frankfurt", "Historia y experiencia" e "Historia intelectual y teoría crítica" (SAZBÓN, 2009).
} 
Revolución Francesa, por estar atada a la memoria de Roma, no pudo producirse «bajo el cielo despejado de la historia»" (Ibídem., p. 166).

Esta hipótesis podría funcionar como un modo de responder a por qué Benjamin retoma a Marx en la Tesis XIV. Lo que él rescataría, sería la crítica marxiana a las citas de los revolucionarios franceses por "el carácter supersticioso" que Marx le atribuía a las mismas; o, en otros términos, por "perderse entre nubes" que no dejan ver con claridad el "verdadero contenido" de sus actos.

Ahora bien, el problema de esta lectura es que, aunque fuera el caso que Benjamin acepte la crítica de Marx a las citas de la Revolución Francesa por ser ilusorias -con lo que quedaría claro por qué Benjamin reivindica a Marx en la Tesis XIV-, de todas maneras, sigue quedando en pie la diferencia fundamental que separa a los autores. Esto es: no se explica el hecho de que Benjamin retome a Marx, precisamente en la Tesis en la que afirma que la revolución se inspira en el pasado.

Otra interpretación puede ser desarrollada tanto a partir de Medianoche en la historia de Manuel Reyes Mate, como de Aviso de incendio de Michael Löwy, dos libros que tienen en común el hecho de comentar pormenorizadamente cada una de las Tesis incluidas en Sobre el concepto de historia. A diferencia de Sazbón, ambos autores entienden que Benjamin no toma a la moda y a la Revolución Francesa como dos maneras análogas de citar el pasado. Por el contrario, para ellos, Benjamin considera las citas de la Revolución Francesa como una de las formas "productivas" de traer el pasado al presente, en contraposición a la moda. Según Löwy y Reyes Mate, Benjamin rescata el modo en que los revolucionarios franceses se apropian de figuras del pasado como referencias actuales, a los efectos de interrumpir una historia marcada por la continuidad monárquica (Cf. MATE, 2009, p. 232 y LÖWY, 2005, p. 141). En este sentido, esta lectura de la Tesis XIV daría cuenta, efectivamente, de la fundamental diferencia entre Marx y Benjamin a la hora de considerar la importancia del pasado para la revolución. No obstante, teniendo en cuenta las contundentes críticas de Marx al modo de apropiarse del pasado de los revolucionarios franceses, el problema es que aún habría que explicar por qué Benjamin termina reivindicando la revolución "tal como la entendió Marx".

Avanzando un paso más en la dirección que marca esta problemática, Reyes Mate sugiere que, a pesar de que Benjamin pase por alto pasajes fundamentales de El Dieciocho Brumario de Luis Bonaparte, el hecho de que aluda a Marx en la Tesis XIV podría fundarse en otros textos del autor (Cf. MATE, 2009, p. 232). Reyes Mate recuerda una carta que el joven Marx le escribiera a Arnold Ruge en 1843, en donde, entre otras cuestiones, sostenía:

Desarrollamos nuevos principios para el mundo a base de los propios principios del mundo. No le decimos al mundo: termina con tus luchas, pues son estúpidas; te daremos la 
verdadera consigna de lucha. Nos limitamos a mostrarle al mundo por qué está luchando en verdad, y la conciencia es algo que tendrá que asimilar, aunque no quiera. (...) Entonces, nuestro lema deberá ser: la reforma de la conciencia, no por medio de dogmas, sino a través el análisis de la conciencia mística, ininteligible a sí misma, ya sea que se manifieste en su forma religiosa o política. Luego será evidente que el mundo ha estado soñando por mucho tiempo con la posesión de una cosa de la cual, para poseerla realmente, debe tener consciencia. Será evidente que no se trata de trazar una línea mental entre el pasado y el presente, sino de materializar los pensamientos del pasado (MARX, 2008).

En estos pasajes, Marx desecha absolutamente el pasado a la hora de pensar el cambio. El pasado no parece ya oprimir, como una pesadilla, el cerebro de los vivos. Es decir, no se piensa aquí en términos de una escisión radical entre pasado y futuro, por el contrario, como también afirma en la carta, “(...) la humanidad no está comenzando una nueva tarea, sino que está llevando a cabo de manera consciente su vieja tarea” (Ibídem.). Según Reyes Mate,

(...) la explicación que da Marx del capital como apropiación de la plusvalía del trabajador tiene un componente anamnético evidente. Lo que deslegitima al capital es el silenciamiento o cosificación de todo ese pasado de sufrimiento que va unido al término de plusvalía, es decir, de apropiación por parte del capitalista de un valor que no es suyo y de desposesión de un valor que es del otro, del trabajador (MATE, 2009, p. 232).

Entendemos que, por esta vía, Reyes Mate busca destacar el hecho de que, para Marx, sólo sacando a la luz el sufrimiento que supone y ha supuesto la acumulación de capital, y la injusticia que trae aparejada la apropiación de la fuerza de trabajo del obrero por parte del capitalista, sólo así cobra sentido y es posible la revolución. Si ésta pretende interrumpir la lógica del beneficio del capitalismo, es imprescindible partir de su desnaturalización, es decir, de traer al presente el modo en que históricamente dicha lógica fue normalizándose a costa del sufrimiento y la injusticia.

Ahora bien, el problema de esta posible explicación acerca de por qué se hace referencia a Marx en la Tesis XIV, es que si bien es cierto que, para Marx, la revolución proletaria debe tener en cuenta la historia pasada, esto no supone que la misma "saque su poesía del pasado". La revolución es impensable sin la consideración del pasado, pero Marx no parece defender que aquélla se inspire en él. La importancia del pasado, en todo caso, radica en la posibilidad de deslegitimar las injusticias presentes, dando voz a lo silenciado por la lógica del capital. No obstante, este procedimiento de historización, el trazado de esta "genealogía" o "génesis" que permite 
“desnaturalizar" el capital, no alude a lo mismo que la "construcción de la historia" que propone Benjamin en las primeras líneas de la Tesis XIV (Cf. BENJAMIN, 1996, p. 61). Como vimos más arriba, la construcción de la historia supone la creación de algo nuevo a partir de poner en conexión con el presente un fragmento del pasado oprimido y clausurado por la historia.

III

Vemos así que las posibles respuestas a las que aludimos, dejan en pie la pregunta acerca de por qué Benjamin retoma a Marx en la Tesis XIV. Y es que, si sólo nos atenemos a los argumentos que se despliegan al interior de los textos de ambos autores, tal vez no haya una respuesta que dé cuenta de manera satisfactoria de este problema. Probablemente, esta cuestión más bien se explique por el hecho de que Benjamin se nutrió de la cultura y el pensamiento marxistas, aunque su acercamiento se dio sólo "en términos de fidelidad a una experiencia de época" (SAZBÓN, 2002, p. 157). Como afirma Sazbón, a diferencia de otros marxistas de su tiempo que partieron de un "control de legibilidad" de los textos de Marx, Benjamin no buscó un acceso erudito a los mismos. Una frecuentación limitada y selectiva de la obra de Marx, le permitió dejar de lado las tensiones del corpus y pudo acercarse al autor en busca de sus propios interrogantes (Ibídem.). Esta lectura "no exegética", aunque comprometida con el proyecto marxista, es posiblemente la razón por la que en la Tesis XIV Benjamin utiliza a Marx en provecho de su propia tesis más allá de la letra de Marx, es decir, pasando por alto pasajes fundamentales de El Dieciocho Brumario de Luis Bonaparte.

Asumiendo, entonces, la falta de una respuesta que sólo atienda al contenido interno de los textos, es preciso destacar que -más allá de las divergencias acerca de si Benjamin coincide o no con Marx en su crítica a las citas de los revolucionarios franceses o sobre qué escritos del autor podría haber tenido en mente al redactar la Tesis XIV- Benjamin no se opondría a Marx cuando éste exhorta a despojarse de toda veneración "supersticiosa" del pasado. Pues también para Benjamin hay referencias al pasado que tienen efectos "conservadores". En el caso de la Tesis XIV, ellas son las citas de la moda. Ésta se caracteriza por seleccionar ciertos fragmentos del pasado que funcionan como supuestas novedades, pero que, efectivamente, no producen ninguna desestabilización del status quo. Las citas de la moda no provocan nada realmente nuevo puesto que responden a la clase dominante (Cf. BENJAMIN, 1996, p. 61) y "los poderosos (...) quieren que todo siga igual, preferiblemente por mil años" (BENJAMIN, 2005 , pp. 99-100) ${ }^{6}$. Esta manera de recurrir al pasado, es similar a la forma

\footnotetext{
${ }^{6}$ Cita de Brecht incluida en el Libro de los Pasajes.
} 
en que operan las evocaciones que Marx criticaba en El Dieciocho Brumario de Luis Bonaparte. Tanto la selección de segmentos del pasado que realiza la moda (para Benjamin), como la utilización de la antigua Roma por parte de los revolucionarios franceses (según Marx), en última instancia no hacen sino ocultar lo que está en juego en la presunta "novedad"7. Así, ambos autores nos advierten que la operación de traer el pasado al presente puede redundar en la reproducción y sostenimiento de las estructuras de poder existente. Al igual que la revolución proletaria para Marx, el cambio que Benjamin propugna también debe liberarse de aquellas citas del pasado que refuerzan las actuales asimetrías sociales.

\section{Referencias bibliográficas}

BENJAMIN, Walter, "Sobre el concepto de historia", en La dialéctica en suspenso. Fragmentos sobre la historia, Santiago de Chile: Arcis-Lom, 1996.

Libro de los Pasajes, Madrid: Akal, 2005.

"Materiales preparatorios del escrito 'Sobre el concepto de historia", en MATE, Manuel Reyes, Medianoche en la historia. Comentario a las tesis de Walter Benjamin 'Sobre el concepto de historia', Madrid: Trotta, 2009.

HORKHEIMER, Max, "El Estado autoritario", en Sociedad en transición: estudios de filosofía social, Barcelona: Planeta-Agostini, 1972.

JANINE RIBEIRO, Renato, La última razón de los reyes, Buenos Aires: Colihue, 1998.

LÖWY, Michael, Walter Benjamin: aviso de incendio, Buenos Aires: Fondo de Cultura Económica, 2005.

MARX, Karl, El dieciocho Brumario de Luis Bonaparte, Buenos Aires: Need, 1998.

------------, "Carta a Arnold Rouge", en Marxists Internet Archive, 2008. Disponible en http://www.marxists.org/espanol/m-e/cartas/m09-43.htm. Acceso: 5/08/14.

\footnotetext{
${ }^{7} \mathrm{Si}$ bien no concierne al objetivo principal de nuestro escrito, con respecto a este punto es preciso dejar asentadas ciertas diferencias entre los autores. En primer lugar, para Marx la fusión de la modernidad con la antigüedad no conducía a la circularidad de lo siempre igual, como la moda en Benjamin. Para Marx, en la época moderna los hombres se confrontan efectivamente con algo nuevo, el problema es que en el momento de llevar a cabo tareas inauditas que implican una ruptura temporal, enmascaran el presente en el pasado por el vértigo que les genera su propia acción. Para Benjamin, en cambio, en la moda lo nuevo no es ciertamente tal, lo que se presenta como novedad es, en realidad, la reproducción de un mismo estado de cosas. En segundo lugar, es también necesario precisar que Benjamin no estaría de acuerdo con la idea de Marx acerca de que la revolución "realiza metódicamente su tarea". Es decir, con la idea de que la revolución proletaria estaría orgánicamente entrelazada con la burguesa, de manera tal que, por etapas o momentos de su desarrollo, se llegaría a aquélla.
} 
MATE, Manuel Reyes, Medianoche en la historia. Comentario a las tesis de Walter Benjamin 'Sobre el concepto de historia', Madrid: Trotta, 2009. OYARZÚN ROBLES, Pablo, "Cuatro señas sobre experiencia, historia y facticidad. A manera de introducción", en La dialéctica en suspenso. Fragmentos sobre la historia, Santiago de Chile: Arcis-Lom, 1996.

SAZBÓN, José, Historia y representación, Buenos Aires: Universidad Nacional de Quilmes, 2002.

-------, Nietzsche en Francia y otros estudios de historia intelectual, Buenos Aires: Universidad Nacional de Quilmes, 2009.

WIZISLA, Erdmut, "Revolution", en Benjamins Begriffe, OPITZ, Michael y WZISLA, Erdmut (eds.), Frankfurt am Main: Suhrkamp, 2000. 